\title{
Comparison of the effects of TripleGates and Gates-Glidden burs on cervical dentin thickness and root canal area by using cone beam computed tomography
}

Kássio SOUSA ${ }^{1}$, Carlos Vieira ANDRADE-JUNIOR ${ }^{2}$, Juliana Melo da SILVA ${ }^{3}$, Marco Antonio Hungaro DUARTE ${ }^{4}$, Gustavo DE-DEUS ${ }^{5}$, Emmanuel João Nogueira Leal da SILVA ${ }^{5}$

\author{
1- Private Practice, Jequié, BA, Brazil. \\ 2- Estácio de Sá University, Rio de Janeiro, RJ, Brazil; Southwest Bahia State University (UESB), Jequié, BA, Brazil. \\ 3- Federal University of Pará, Belém, PA, Brazil. \\ 4- Departament of Operative Dentistry, Endodontics and Dental Materials, Bauru School of Dentistry, University of São Paulo, Bauru, SP, Brazil. \\ 5- Health Sciences Center, Grande Rio University (Unigranrio), Rio de Janeiro, RJ, Brazil.
}

Corresponding address: Emmanuel João Nogueira Leal Silva - Rua Herotides de Oliveira, 61/902 - Icaraí - Niterói - RJ - Brazil - Phone: $55218357-5757$ - e-mail: nogueiraemmanuel@hotmail.com

Submitted: February 18, 2014 - Modification: June 9, 2014 - Accepted: June 18, 2014

\section{ABSTRACT}

\begin{abstract}
The search for new instruments to promote an appropriate cervical preparation has led to the development of new rotary instruments such as TripleGates. However, to the best of the authors' knowledge, there is no study evaluating TripleGates effect on the "risk zone" of mandibular molars. Objectives: The aim of this study was to evaluate the effects of a crown-down sequence of Gates-Glidden and TripleGates burs on the remaining cervical dentin thickness and the total amount of dentin removed from the root canals during the instrumentation by using cone beam computed tomography. The number of separated instruments was also evaluated. Material and Methods: Mesial roots of 40 mandibular first molars were divided into 2 equal groups: crown-down sequence of Gates-Glidden (\#3, \#2, \#1) and TripleGates burs. Cervical dentin thickness and canal area were measured before and after instrumentation by using cone beam computed tomography and image analysis software. Student's t-test was used to determine significant differences at $p<0.05$. Results: No significant differences ( $p>0.05$ ) were observed between the instruments, regarding the root canal area and dentin wall thickness. Conclusion: Both tested instruments used for cervical preparation were safe to be used in the mesial root canal of mandibular molars.
\end{abstract}

Keywords: Endodontics. Root canal therapy. Dental instruments.

\section{INTRODUCTION}

It has been found that preflaring the coronal portion of the root canal provides advantages in irrigation efficacy, apical control, cone fit, and compaction procedures ${ }^{9,10,13,16,18}$. However, excessive dentin removal, as a result of cervical preflaring, especially in curved and narrow canals, may cause perforation of the concavity located in the furcation region ${ }^{5,6,11,14}$.

The first rotary instruments used for the cervical preflaring were the Gates-Glidden (GG) burs ${ }^{19}$. Its low cost and high cutting power associated to its simplicity of use made it a commonly used instrument during endodontic procedures. The diameter of the Gates-Glidden bur \#2 $(0.70 \mathrm{~mm})$ is generally considered safe for the cervical preflaring of the mesial canals of mandibular molars ${ }^{24}$; however, the use of higher diameters could promote significant dentin removal at the furcal aspect of the root canal, increasing the risk of a striping perforation in the $\operatorname{root}^{6,8,23,24}$.

The search for new instruments to promote an appropriate cervical preparation has led to the development of new rotary instruments such as TripleGates (Helse, Santa Rosa de Viterbo, SP, 
Brazil). The manufacturer claims that this stainless steel instrument receives a nanotechnology treatment which increases its resistance and reduces friction in dry conditions. Its tip is equivalent to an inactive file 30 and it has 50, 70 and $90 \mathrm{~mm}$ diameters. This instrument has similar active portion with more conical conformation and enhanced intermediate than Gates-Glidden (Figure 1). It should replace Gates-Glidden \#1, \#2 and \#3 and can be used in cervical preflaring with the advantage of performing lateral movement. Moreover, this bur would have the following major advantages: faster instrumentation and lower cost; one bur only can replace all the different sizes of traditional burs, such as Gates, Largo, and Peeso, with no need for instrument change during treatment; increased safety, as a result of its shape, which limits bur action to the cervical third of the root canal and thus avoids any contact with critical areas of the furcation region; adaptability to different root canal anatomic variations and preparation techniques; and versatility because it can be mounted on the engine available at the practitioner's office. Although its predecessor (CPdrill) has been recently evaluated regarding the effect in the "risk zone" of mandibular molars ${ }^{10}$, to the best of the author's knowledge, there is no study evaluating the new preflaring bur TripleGates.

Thus, the aim of this study was to evaluate, by cone beam computed tomography analysis, the effects of cervical preflaring on mesial root canals of mandibular molars utilizing a crown-down sequence of Gates-Glidden burs and the TripleGates instrument. The null hypothesis tested was that there was no difference in the effects of the cervical preflaring on the mesial root canals of mandibular molars when using different cervical preflaring instruments.

\section{MATERIAL AND METHODS}

This study was revised and approved by the Ethics Committee, Nucleus of Collective Health Studies (no. 2134/CEP - HUPE). A sample of 40 human first mandibular molars that had been stored in $5 \%$ formol saline was selected from tooth bank. Roots were initially inspected by stereomicroscopy under $12 \mathrm{X}$ magnification to exclude teeth with any preexisting craze lines or cracks. A digital radiograph in a buccolingual direction was taken to determine the curvature angle of the mesial root using and open source image analysis program (Fiji v.1.47n; Fiji, Madison, WI, USA). Only teeth with a slight curvature of the mesial root (ranging from $0^{\circ}$ to $10^{\circ}$ ) were selected. Teeth not patent to the canal length with a size $10 \mathrm{~K}$-file (Dentsply-Maillefer, Ballaigues, Switzerland) were also discarded. Subsequently, the 40 teeth were pair-matched according to their shape and dimension, and one tooth from each pair was randomly distributed (using the website http://www. random.org) into 2 experimental groups $(n=20)$.

Afterwards, the teeth were embedded in acrylic resin blocks using a flask system measuring $20 \mathrm{~mm}$ in height and $20 \mathrm{~mm}$ in width. After acrylic resin curing, each tooth block was removed, and the initial image was obtained by a cone beam computed tomography (CBCT) (Kodak 9000C 3D, Kodak, Atlanta, GA, USA) using an acrylic resin apparatus. The exposure time was 32.4 seconds, operating at $60 \mathrm{kV}$ and $10 \mathrm{~mA}$. At this moment, the area of each mesial canal, as well as the shortest distance from the root canal to the mesial and distal root surface, was measured $3 \mathrm{~mm}$ below the root furcation, using the CS 3D Imaging Software (Kodak, Atlanta, GA, USA) (Figure 2A).

After capture and initial analysis of the mesial root canals, the GG drills (Dentsply-Maillefer, Ballaigues, Switzerland) were used in crown down order (GG \#3, GG \#2 and GG \#1) in the mesial canals. To operate the drills, a conventional low-speed hand piece operating at $2.500 \mathrm{rpm}$ was used. The movement performed with the rotary instruments was slight apical pressure, upped and downed with only one penetration with each drill. The depth of the drill was determined by its clinging inside the radicular canal usually observed $3 \mathrm{~mm}$ below the entrance of the canals. TripleGates was used with the same technique as described for Gates-Glidden burs. One experienced operator performed all treatments. Previously to instrumentation, canals were irrigated and flooded with $1 \mathrm{~mL}$ of $5.25 \% \mathrm{NaOCl}$ using a 30-gauge Endo-Eze Tip (Ultradent Products Inc., South Jordan, UT, USA). Between each preparation step, root canals were irrigated with $1 \mathrm{~mL}$ of $5.25 \%$

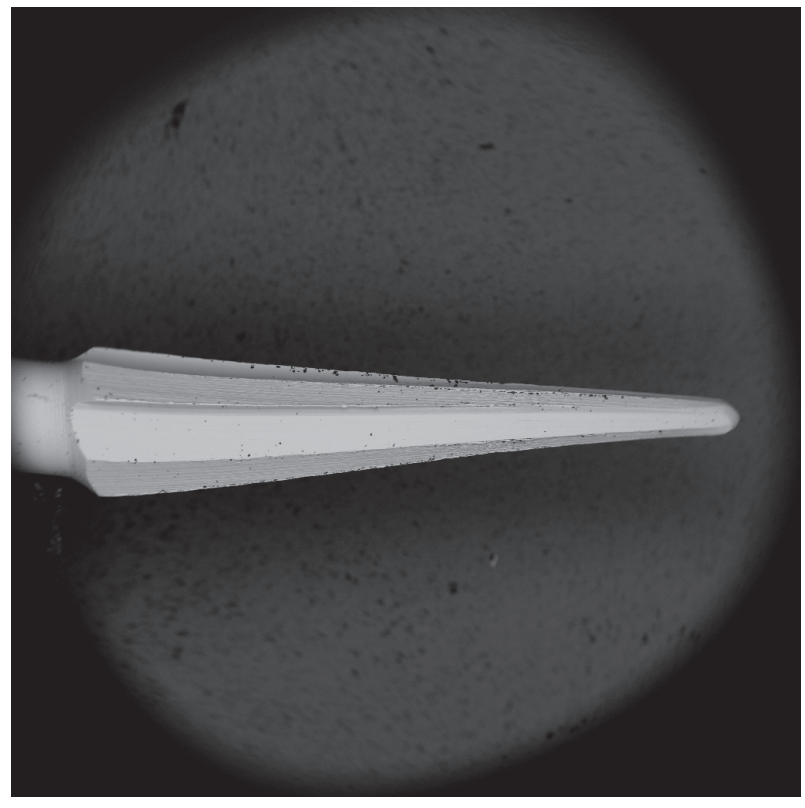

Figure 1-Scanning electron microscope photomicrograph (X10) showing the TripleGates instrument 

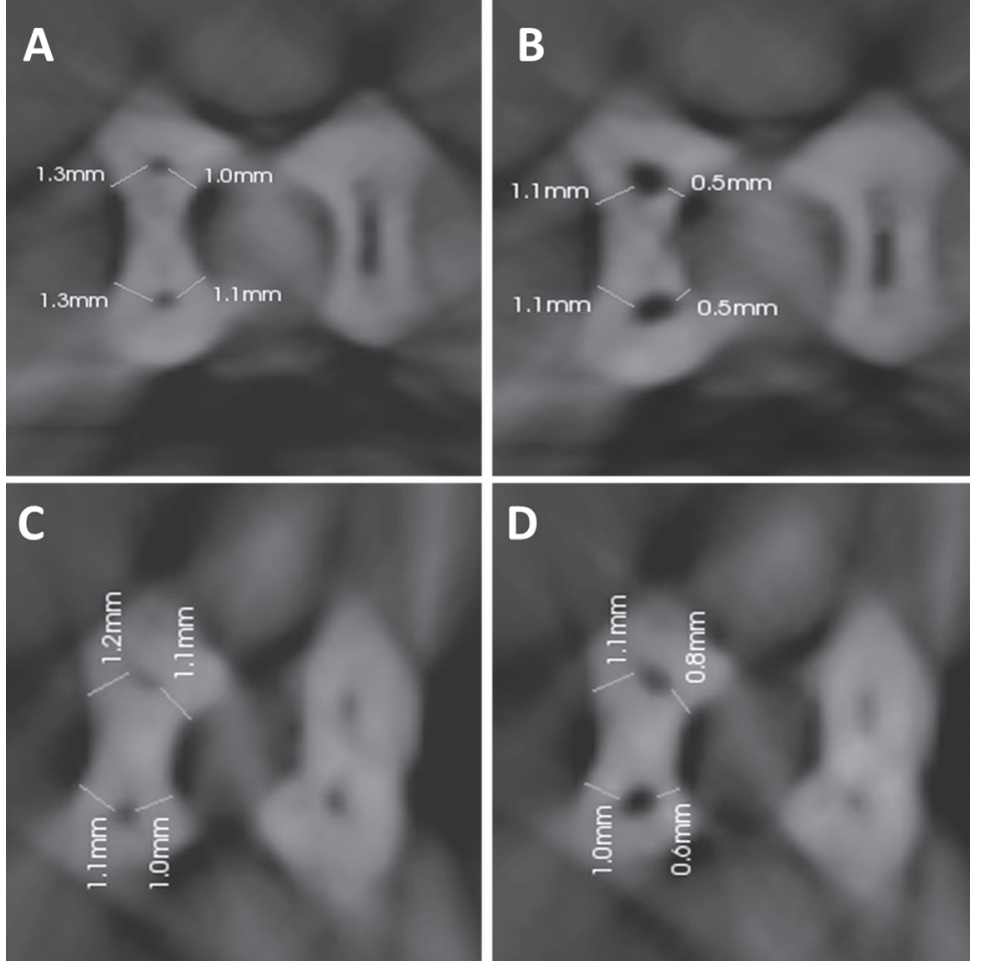

Figure 2- A) Example of a preoperative image in the Gates-Glidden group; B) Postoperative image in Gates-Glidden group; C) Example of a preoperative image in TripleGates group; D) Postoperative image in TripleGates group

$\mathrm{NaOCl}$. After preparation, canals were irrigated with $1 \mathrm{~mL} 5.25 \% \mathrm{NaOCl}$ in the GG group and $4 \mathrm{~mL}$ $5.25 \% \mathrm{NaOCl}$ in the TripleGates group. A total of 5 $\mathrm{mL} 5.25 \% \mathrm{NaOCl}$ was used in both groups.

After the instrumentation, each tooth block was submitted to a new CBCT exam and new images of the mesial root canal were captured. At this

Table 1- Mean and standard deviation (SD) of the canal area increase in percentages after the use of the tested instruments

\begin{tabular}{cc}
\hline Group & Mean \pm SD \\
\hline Gates-Glidden & $52.8 \pm 31.7^{\mathrm{A}}$ \\
TripleGates & $44.8 \pm 28.8^{\mathrm{A}}$ \\
\hline
\end{tabular}

Same letters represent no statistically significant difference $(p<0.05)$ moment, the area of each mesial canal, as well as the shortest distance from the root canal to the mesial and distal root surface, was measured in the after-instrumentation image, $3 \mathrm{~mm}$ below the root furcation, using the CS 3D Imaging Software (Kodak, Atlanta, GA, USA) (Figure 2B).

The total area of the root canal before and after the use of each instrument was measured. Subsequently, the increase of the instrumented area in terms of percentage was calculated. Later, the thickness of the mesial and distal walls (danger zone) was established. All measurements were performed using CS 3D Imaging Software (Kodak). Data were subjected to statistical analysis. Comparisons of the increase of the instrumented area and dentin thickness among the groups were performed using Student's t-test. The significance level was set at $5 \%$.

Table 2- Means (mm) and standard deviation (SD) of dentin wall thickness on the initial and postinstrumentation images and percentage reduction in each group at the mesial and distal aspects of the root canal

\begin{tabular}{ccccc}
\hline Images & Gates-Glidden & \multicolumn{3}{c}{ TripleGates } \\
& Mesial & Distal & Mesial & Distal \\
\hline Initial & $1.35 \pm 0.17 \mathrm{~mm}$ & $1.11 \pm 0.16 \mathrm{~mm}$ & $1.32 \pm 0.17 \mathrm{~mm}$ & $1.09 \pm 0.15 \mathrm{~mm}$ \\
Final & $1.15 \pm 0.16 \mathrm{~mm}$ & $0.65 \pm 0.19 \mathrm{~mm}$ & $1.10 \pm 0.18 \mathrm{~mm}$ & $0.60 \pm 0.18 \mathrm{~mm}$ \\
Reduction (\%) & $14.22 \pm 3.2 \%^{\mathrm{A}}$ & $42.50 \pm 6.7 \%^{\mathrm{B}}$ & $16.71 \pm 4.5 \%^{\mathrm{A}}$ & $45.00 \pm 8.3 \%^{\mathrm{B}}$ \\
\hline
\end{tabular}

Different letters indicate statistical significant differences between the percentage of wear of the mesial and distal wall provided by the instruments tested $(p<0.05)$. 


\section{RESULTS}

Table 1 presents the increase of the instrumented area in terms of percentage. No significant differences $(p>0.05)$ were observed among the instruments. Table 2 shows the mean and standard deviation of dentin wall thickness on the initial and postinstrumentation images for each group in millimeters. No perforation was observed in any of the tested groups. Also, no statistically significant differences $(p>0.05)$ were found among the groups for the preoperative dentin wall thickness at the mesial and the distal aspects of the root. No statistically significant differences $(p>0.05)$ were found for the postoperative dentin thickness among the groups after the use of the preflaring instruments.

\section{DISCUSSION}

Preflaring of the cervical third decreases the tension of manual and rotary instruments during apical instrumentation by eliminating dentin projections ${ }^{4}$, and also provides greater reliability when defining the working length and the apical gauging ${ }^{12}$. Moreover, when prepares with NiTi instruments without the pre-enlargement in the cervical region with stainless steel instruments, there is a greater action of the NiTi instruments on the wall of the furcation, reducing the dentin thickness to values below $0.5 \mathrm{~mm}^{24}$. This fact occurs specially with instruments with conical core and large volume of metal mass in the central axis such as the ProTaper instruments ${ }^{24}$. During the last few decades, a number of methodologies have been described to assess the effect of endodontic instruments on dentin wall thickness, including plastic models ${ }^{22}$, histologic sections ${ }^{21}$, scanning electron microscopic studies ${ }^{15}$, serial sectioning 6,8,23 and radiographic comparisons ${ }^{2}$. In the present study, СВCT was used to analyze the cervical dentin thickness and root canal area of mandibular molars. This methodology permits observations of the root canal in three-dimensional planes (axial, transverse, and tangent planes) and allows preinstrumentation and postintrumentation measuring of root canal volume and hence calculations of the amount of removed dentin during preflaring of the root canal without complicate procedures, destructive sectioning of the specimens, or loss of the root material during sectioning. In addition, CBCT scans allow easy measurement of canal changes, because image has an accurate scale, decreasing the potential of a radiographic or photographic transfer error ${ }^{20}$.

The furcation area of the first mandibular molars, sectioned at a point located between 2 and $3 \mathrm{~mm}$ below the furcation of the roots, presented a concave aspect in $100 \%$ of the mesial roots ${ }^{3}$. Several authors have described an area 3 to $4 \mathrm{~mm}$ below the entrance of the canals to be the most sensitive location for the perforation of mesial molar roots after the use of rotary instruments ${ }^{4,6,12}$. Based on these results, the present study opted to evaluate and measure the dentin thickness $3 \mathrm{~mm}$ below the furcation of the roots.

In the present study, a Gates-Glidden crowndown sequence was compared to the TripleGates instrument. The option to use a crown-down sequence was based on a previous study ${ }^{6}$ that showed a greater remaining dentine/cementum thickness when using Gates-Glidden burs in the crown-down sequence than in a serial sequence. In that study, the tendency of greater wear after use a serial sequence could be seen in two samples, in which a total rupture of the dentine/cementum wall leading to the furcation area could be observed. Throughout this experiment, it was observed that samples always suffer greater wear nearest to the distal surface (Risk Zone) rather than the mesial surface (Safety Zone), which was also seen in previous studies ${ }^{1,6-8,23,25}$.

The tested null hypothesis was sustained in the present study as our comparison did not reveal any statistically significant differences between the tested groups because the mean percentage of canal area increase and the dentin wall thickness was similar in the canals as shown in Table 1 and Table 2. Also, no cervical root perforation was observed in the present study. However, the TripleGates technique consumed less time than the Gates-Glidden sequence (data not shown). No file separation was observed in the TripleGates group; however five Gates-Glidden (three GG \#1 and two GG \#2) separations were observed in the present study.

In this study it was observed that the wear of the distal wall (Risk Zone) of the mesial canals of mandibular molars was significantly greater than the wear of the mesial wall (Safety Zone) $(p<0.05)$, with no differences between the wear promoted between drills compared. Similar results were observed previously $4,6,17$. Both GG and TP left an average remaining dentin thickness of approximately $0.6 \mathrm{~mm}$ in the distal wall (Table 2). Moreover, the present results are also similar to those obtained when $\mathrm{NiTi}$ files were used ${ }^{24}$. Remaining dentine thickness following several intra-radicular procedures may be the most important iatrogenic factor correlating to future root resistance against fracture ${ }^{17}$. Excessive flaring of the cervical and middle thirds in flat roots may lead to a pronounced decrease of the dentinal wall thickness or even result in a strip perforation towards the furcation ${ }^{5,11}$. Thin dentine walls increase root permeability and the possibility of fracture, not only during filling, but also during tooth functioning ${ }^{25}$. The remaining dentin of $0.6 \mathrm{~mm}$ obtained in this study does not appear to compromise the tooth 
structure. It has been previously established that a limit of 0.2 and $0.3 \mathrm{~mm}$ of dentine thickness as a measurement in which the resultant forces of condensation during filling would not result in tooth fracture ${ }^{14}$. Having this in mind and through the results of the present study it was possible to conclude that both instruments offer the operator a great safety margin.

\section{CONCLUSIONS}

Our results showed that both tested instruments used for cervical preparation were safe to be employed in the mesial root canal of mandibular molars.

\section{ACKNOWLEDGEMENTS}

This work was supported by São Paulo Research Foundation (FAPESP), process no. 2012-06738-9.

\section{REFERENCES}

1- Abou-Rass M, Frank AL, Glick DH. The anticurvature filing method to prepare the curved root canal. J Am Dent Assoc. 1980;101:792-4. 2- Abou-Rass M, Jastrab RJ. The use of rotary instruments as auxiliary aids to root canal preparation of molars. J Endod. 1982;8:78-82.

3- Bower RC. Furcation morphology relative to periodontal treatment. Furcation entrance architecture. J Periodontol. $1979 ; 50: 23-7$

4- Constante IG, Davidowicz H, Barletta FB, Moura AA. Location and angulation of curvatures of mesiobucal canals of mandibular molars debrided by three endodontic techniques. Braz Oral Res. 2007;21:22-8

5- Coutinho-Filho T, De-Deus G, Pinto TG, Gurgel-Filho ED, ManigliaFerreira C. A computer evaluation of the dentin remaining after cervical preparation in curved canals: gates-glidden drills vs. orifice shaper. Braz J Oral Sci. 2002;1:116-20.

6- Coutinho-Filho T, De-Deus G, Gurgel-Filho ED, Rocha-Lima AC, Dias KR, Barbosa CA. Evaluation of the risk of a stripping perforation with Gates-Glidden drills: serial versus crown-down sequences. Braz Oral Res. 2008;22:18-24.

7- Cunningham CJ, Senia SE. A three-dimensional study of canal curvatures in the mesial roots of mandibular molars. J Endod. 1992;18:294-300.

8- Duarte MA, Bernardes RA, Ordinola-Zapata R, Vasconcelos BC, Bramante CM, Moraes IG. Effects of Gates-Glidden, LA Axxess and orifice shaper burs on the cervical dentin thickness and root canal area of mandibular molars. Braz Dent J. 2011;22:28-31.
9- Fava LR. The double-flared technique: an alternative for biomechanical preparation. J Endod. 1983;9:76-83.

10- Flores CB, Montagner F, Gomes BP, Dotto GN, Silva Schmitz $M$. Comparative assessment of the effects of Gates-Glidden, Largo, LA-Axxess, and New Brazilian Drill CPdrill on coronal preenlargement: cone-beam computed tomographic analysis. J Endod. 2014;40:571-4.

11- Isom TL, Marshall JG, Baumgartner JC. Evaluation of root thickness in curved canals after flaring. J Endod. 1995;21:368-71. 12- Lazzaretti DN, Camargo BA, Della Bona A, Fornari VJ, Vanni JR, Baratto Filho $F$. Influence of different methods of cervical flaring on establishment of working length. J Appl Oral Sci. 2006;14:351-4. 13- Leeb J. Canal orifice enlargement as related to biomechanical preparation. J Endod. 1983;9:463-70.

14- Lim SS, Stock CJ. The risk of perforation in the curved canal: anticurvature filing compared with the step-back technique. Int Endod J. 1987;20:33-9.

15- Mizrahi SJ, Tucker JW, Seltzer S. A scanning electron microscopic study of the efficacy of various endodontic instruments. J Endod. 1975; 1:324-33.

16- Morgan LF, Montgomery S. An evaluation of the crown-down pressureless technique. J Endod. 1984;10:491-8.

17- Pilo R, Corcino G, Tamse A. Residual dentin thickness in mandibular premolars prepared with hand and rotatory instruments. J Endod. 1998;24:401-4.

18- Ram Z. Effectiveness of root canal irrigation. Oral Surg Oral Med Oral Pathol Oral Radiol Endod. 1977;44:306-9.

19- Schilder H. Cleaning and shaping the root canal. Dent Clin North Am. 1974;18:269-96

20- Uyanik MO, Cehreli CZ, Mocan BO, Dagli FT. Comparative evaluation of three nickel-titanium instrumentation systems in human teeth using computed tomography. J Endod. 2006;32:66871.

21- Walton RE. Histologic evaluation of different methods of enlarging the pulp canal space. J Endod. 1976;2:304-11.

22- Weine FS, Kelly RF, Lio PJ. The effect of preparation procedures on original canal shape and on apical foramen shape. J Endod. $1975 ; 1: 255-62$.

23- Wu MK, van der Sluis LW, Wesselink PR. The risk of furcal perforation in mandibular molars using Gates-Glidden drills with anticurvature pressure. Oral Surg Oral Med Oral Pathol Oral Radiol Endod. 2005;99:378-82.

24- Yang G, Yuan G, Yun X, Zhou X, Liu B, Wu H. Effects of two nickel-titanium instrument systems, MTwo versus ProTaper universal, on root canal geometry assessed by micro-computed tomography. J Endod. 2011;37:1412-6.

25- Zuckerman O, Katz A, Pilo R, Tamse A, Fuss Z. Residual dentin thickness in mesial roots of mandibular molars prepared with Lightspeed rotary instruments and Gates-Glidden reamers. Oral Surg Oral Med Oral Pathol Oral Radiol Endod. 2003;96:351-5. 